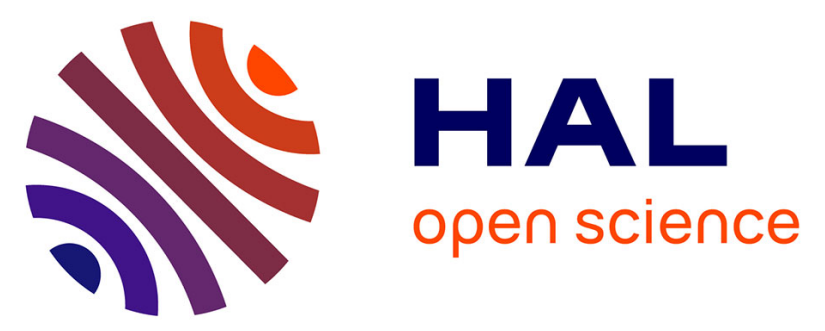

\title{
Biobjective control of emulsion polymerizations: control of the polymer composition and the concentration of monomer in the polymer particles
}

\author{
Nida Sheibat-Othman, Gilles Fevotte, Timothy Mckenna
}

\section{To cite this version:}

Nida Sheibat-Othman, Gilles Fevotte, Timothy Mckenna. Biobjective control of emulsion polymerizations: control of the polymer composition and the concentration of monomer in the polymer particles. Chemical Engineering Journal, 2004, 98 (1-2), pp.69-79. hal-00358753

HAL Id: hal-00358753

https://hal.science/hal-00358753

Submitted on 17 Feb 2009

HAL is a multi-disciplinary open access archive for the deposit and dissemination of scientific research documents, whether they are published or not. The documents may come from teaching and research institutions in France or abroad, or from public or private research centers.
L'archive ouverte pluridisciplinaire HAL, est destinée au dépôt et à la diffusion de documents scientifiques de niveau recherche, publiés ou non, émanant des établissements d'enseignement et de recherche français ou étrangers, des laboratoires publics ou privés. 


\section{This document must be cited according to its final version which is published in:}

\section{Chemical Engineering Journal 98 (2004) 69-79}

http://www.elsevier.com/wps/find/journaldescription.cws_home/601273/de scription\#description

All open archive documents of Nida Sheibat-Othman are available at:

\section{http://hal.archives-ouvertes.fr/NIDA-SHEIBAT-OTHMAN}

The professional web page of Nida Sheibat-Othman is:

http://www-

lagep.cpe.fr/wwwlagep6/fr/fr_Individu.php?ve_sNom=SHEIBAT $\underline{\% 20-O T H M A N \& v e \_s P r e n o m=N i d a \& v e \_s L a n g u e=f r}$ 


\title{
Biobjective control of emulsion polymerizations: control of the polymer composition and the concentration of monomer in the polymer particles
}

\author{
Nida Sh'eibat Othman ${ }^{1 *}$, Gilles Févotte ${ }^{1}$ and Timothy .F. McKenna ${ }^{2}$ \\ ${ }^{1}$ LAGEP-Université yon I and ${ }^{2}$ LCPP-CNRS/ESCPE, Bât 308, 43 Blvd. du 11 Nov. 1918, 69622 \\ Villeurbanne CEDEX, France
}

\begin{abstract}
A decoupled control law is proposed to control the concentration of monomer in the polymer particles in emulsion homopolymerization, copolymerization and terpolymerization processes and simultaneously to insure the production of a homogeneous polymer composition. Nonlinear geometric controllers are used to calculate the monomer flow rates that accomplish this purpose. The controllers are based on the estimation of the residual number of moles of free monomer that is obtained by calorimetry and by using nonlinear high gain observers in this work. The technique is experimentally validated using the butyl acrylate, methyl methacrylate and vinyl acetate monomers.
\end{abstract}

Keywords: Input-output linearizing control, state observers, polymerization processes.

\section{Introduction:}

Much work has been done on the control of emulsion polymerizations (Gloor et al. [1], Buruaga et al.[2], Arzamendi and Asua [3]). Control objectives can be set for many reasons, including maximization of productivity, process safety, and especially the maintenance of polymer quality in terms of chemical composition, the molecular weight distribution, etc.

These goals are often conflicting. For instance, maximizing productivity means maintaining the rate of reaction at its highest possible value (under safe conditions). This can mean keeping high polymer contents inside the particles. On the other hand, minimizing gel formation can imply keeping monomer concentrations as low as possible.

* Corresponding author: Tel. 33-4-72-46-18-50; Fax: 334.72.43.16.99;E-mail: nida.othman@lagep.univ-lyon1.fr
In a free radical emulsion polymerization, the reaction occurs in small particles of the order of 10 to 100 nanometers in diameter. The rate of reaction is typically described by an equation of the form:

$$
\mathrm{R}_{\mathrm{P}}=\overline{\mathrm{K}}_{\mathrm{P}}\left[\mathrm{M}_{\mathrm{P}}\right] \frac{\overline{\mathrm{n}} \mathrm{N}_{\mathrm{P}}}{\mathrm{N}_{\mathrm{A}}} \mathrm{V}
$$

where $R_{P}$ is the rate of reaction $\left(\mathrm{mol} / \mathrm{cm}^{3} / \mathrm{s}\right), \bar{k}_{P}$ an effective rate constant, $\left[\mathrm{M}_{\mathrm{P}}\right]$ the concentration of monomer in the particles $\left(\mathrm{m} / \mathrm{cm}^{3}\right), \bar{n}$ is the average number of radicals per particle, $\mathrm{N}_{\mathrm{P}}$ is the number of particles per $\mathrm{cm}^{3}, \mathrm{~V}$ the reactor volume, and $\mathrm{N}_{\mathrm{A}}$ is Avogadro's number. $K_{P}$ is a function of the composition (see below). $\left[\mathrm{M}_{\mathrm{P}}\right]$ will vary between 0 and an upper limit set by thermodynamic concentrations. This upper limit is called the saturation concentration and any monomer present in excess, i.e. once the particles are saturated, will be localized in a separate droplet phase where no reaction takes place. 
In emulsion polymerization, the main locus of the reaction is the polymer particles. Therefore, the overall behavior of the process depends on the number and size of polymer particles, on the concentration of reactive spices in the polymer particles, and on the reactor temperature. These variables therefore constitute the major quantities that one can manipulate in the control of and emulsion polymerization. However, the particle size and number are usually fixed a priori for quality reasons. Also, the reaction temperature is usually predetermined for reasons related to product quality and security. Also, using the reaction temperature to control the process productivity requires an improved study of the simultaneous temperature effect on the evolution of the final polymer properties (latex stability in particular). Therefore, controlling the concentrations of monomer and radicals in the polymer particles seems to be one of the best ways to control the process. The concentration of radicals in polymer particles is usually not known, and is difficult to model precisely. It is very sensitive to inhibiting impurities and is governed by several factors, such as diffusion, adsorption and desorption phenomena that are not usually well understood and are difficult to manipulate explicitly. For these reasons, the process is usually controlled by manipulating the concentration of monomer in the particles.

It should be noted however that the concentration of radicals in the polymer particles depends in a way on the concentration of monomer. The radical mobility in the polymer particles, and therefore radical termination, increases with increasing the concentration of monomer in the polymer particles. This means that these two variables cannot be decoupled and using the concentration of monomer in the polymer particles to maximize productivity requires a study on the effect of the concentration of monomer on the concentration of radicals. This is the unique way to maximize the reaction rate and to ensure the process security.

In this work we focus on controlling the concentration of monomer in the polymer particles. Controlling the concentration of monomer is indispensable for several applications. First of all, this allows us to avoid the existence of monomer droplets. Monomer droplets might favorite the reaction in the aqueous phase for water slightly soluble monomers, or might destabilize the latex and might provoke unwanted nucleation, thereby changing the particle size distribution. Minimizing the concentration of monomer in the reactor allows us also to minimize the risk of a runaway reaction.

The objective of this work is to maintain the concentration of monomer in the polymer particles $\left[\mathrm{M}_{\mathrm{P}}\right]$ at a set-point less than the saturation point, while maintaining the polymer composition constant in the case where two or three monomers are involved in the reaction. The literature (Hamielec et al. [4], Arzamendi and Asua [5], and Canu et al. [6]) shows that the most widely applied approach for composition control consists of introducing a mixture of monomers at the desired composition. However, in order to obtain good composition control with this technique it is necessary to use a very low flow rate of preemulsion, otherwise the less reactive monomer(s) will be accumulated in the reactor and the monomer composition will drift, thereby causing the polymer composition to drift. Therefore, the best method for controlling the polymer composition consists of adding the monomers separately, in order to maintain the monomer composition in the reactor constant, (see Arzamendi and Asua [5]). In this case, the less reactive monomer can be charged at the beginning of the reaction, or be added semi-continuously in order to maximize the process productivity. This technique allows us to produce polymers with a constant composition and to maximize the process productivity by minimizing the process feed time.

In our work, no attempt was made to calculate the heat removal capacity of the 3 liters reactor calorimeter we used to test the control laws. We assume that the jacket is able to evacuate all the amount of heat produced even under saturation conditions. Preliminary experiments (not essentials here) showed that this is indeed the case. Simultaneously, the co- and terpolymer composition must remain constant at all times. In the first part of this work, we develop a control strategy to maintain the concentration of monomer in the polymer particles in emulsion homopolymerization at a set level. In this case, there is no problem of composition control. Next, we develop controllers for $\left[\mathrm{M}_{\mathrm{P}}\right]$ in emulsion coand terpolymerization processes that allow us to 
simultaneously control the polymer composition. In the case of emulsion copolymerization, the flow rate of the less reactive monomer is used to maximize the concentration of monomer in the polymer particles, and the composition controller uses the flow rate of the most reactive monomer. In the terpolymerization case, the composition controller contains 2-coupled controllers that manipulate the flow rates of the two more reactive monomers. This is coupled with a third controller that regulates the concentration of monomer in the polymer particles.

\section{Homopolymerization processes}

Several polymers are produced by means of batch, semi-continuous or continuous homopolymerization processes, e.g. polystyrene (PS), polyvinylacetate (PVA), polymethylmethacrylate (PMMA) and polybutylacrylate (PBA). Several studies treated the modeling of emulsion homopolymerization, e.g. Lin and Chiu [7], Schork and Ray [8], Gilmore et al. [9] and Penlidis et al. [10]. The control of emulsion homopolymerization reactors was less studied than solution reactors. We can however mention, Semino and Ray [11,12], for the population control and Jang and Lin [13] for the control of batch polymerization of vinyl acetate, by manipulating the temperature. In our work, we use nonlinear control laws in order to control the homopolymerization process by manipulating the flow rate of monomer. This is a preliminary step in order to test the control robustness that will be applied then on complex systems such as co- and terpolymerizations.

In order to maintain the amount of free monomer lower than the saturation concentration, we require the measurement of $\left[\mathrm{M}^{\mathrm{P}}\right]$ at every moment. In the experiments realized in this work, calorimetry was used to monitor the process (Othman et al. [14]). Calorimetric measurements give us an estimate of the heat produced by the reaction and of the overall monomer conversion. Since the monomer flow rate $(\mathrm{Q})$ is measured online, we can assume that the number of moles of residual monomer $(\mathrm{N})$ is estimated on-line.

The material balance of a semi-continuous homopolymerization is the following:

$$
\dot{\mathrm{N}}=\mathrm{Q}-\mathrm{R}_{\mathrm{P}}
$$

In emulsion homopolymerization, the reaction rate of monomer is proportional to $\mu,\left[\mathrm{M}^{\mathrm{P}}\right]$ and to the monomer propagation constant, $\mathrm{K}_{\mathrm{P}}$, according to the following equation:

$$
\mathrm{R}_{\mathrm{P}}=\mathrm{K}_{\mathrm{P}} \mu\left[\mathrm{M}^{\mathrm{P}}\right]
$$

The concentration of radicals in polymer particles is given by:

$$
\mu=\frac{\bar{n} N_{P}^{T}}{N_{A}}
$$

If we assume that $K_{P}$ is constant since the reactor temperature is usually maintained constant, material balance 2 shows that the reaction rate is determined by two main parameters: the number of moles of radicals, $\mu$, and the concentration of monomer in the polymer particles, $\left[\mathrm{M}^{\mathrm{P}}\right]$. Therefore, the maximum productivity is obtained when the product $\mu\left[\mathrm{M}^{\mathrm{P}}\right]$ is maximized. If these two parameters are independent, we can then maximize each of them separately, or maximize one of them, in order to maximize $R_{P}$. However, as we show below, $\left[\mathrm{M}^{\mathrm{p}}\right]$ can influence $\mu$ at high polymer concentrations because of the well-known gel effect (Gilbert [15]). Therefore maximizing $\left[\mathrm{M}^{\mathrm{P}}\right.$ ] does not necessarily maximize $\mathrm{R}_{\mathrm{P}}$. The model of $\mu$ is not well known and is therefore not easily controlled. For these reasons, we will concentrate on maximizing the concentration of monomer in the polymer particles.

In order to control the concentration of monomer in the polymer particles, we require an estimate of $\left[\mathrm{M}^{\mathrm{P}}\right]$ and $\mathrm{R}_{\mathrm{P}}$ which can be found by calorimetry. Therefore, we propose to construct an estimator of $\mathrm{N}$ and $\mu$ based on the calorimetric measurements. The observer will allow us to filter $\mathrm{N}$ and to obtain an estimate of the unknown variable $\mu$ on-line. Estimating $\mu$ during the reaction is very important. Since it provides a great deal of information about the process, e.g. reaction rate (which allow us to estimate the heat produced by the reaction), and can be used to estimate molecular weight and the particle size and number.

To estimate $\left[\mathrm{M}^{\mathrm{P}}\right]$ and $\mu$ we will construct a high gain nonlinear observer. The model output is based on the calorimetric measurements. In semicontinuous homopolymerization, the number of residual moles of monomer can be directly determined from the conversion, as follows: 


$$
X_{g}=\frac{\left(N^{T}-N\right)}{N^{T}}=1-\frac{N}{N^{T}}
$$

The total number of moles of free monomer at time $t$ is the initial number of moles $\mathrm{N}_{0}$ plus the sum of the molar flow rate (Q) added up to time (t):

$$
\mathrm{N}^{\mathrm{T}}=\mathrm{N}_{0}+\int_{0}^{\mathrm{t}} \mathrm{Qdt}
$$

The concentration of monomer in the polymer particles depends on the maximum saturation of particles during interval II (droplets present, $\left[\mathrm{M}^{\mathrm{P}}\right]=\left[\mathrm{M}^{\mathrm{P}}\right.$ sat $\left.]\right)$ and in interval III $\left(\left[\mathrm{M}^{\mathrm{P}}\right]<\left[\mathrm{M}^{\mathrm{P}}{ }_{\text {sat }}\right]\right)$ :

$$
\left[\mathrm{M}^{\mathrm{P}}\right]=\left\{\begin{array}{l}
\frac{\left(1-\phi_{\mathrm{p}}^{\mathrm{p}}\right) \rho}{\mathrm{MW}}, \quad \text { Interval II } \\
\frac{\mathrm{N}}{\mathrm{MW}\left(\left(\mathrm{N}^{\mathrm{T}}-\mathrm{N}\right) / \rho_{\mathrm{h}}+\mathrm{N} / \rho\right)}, \text { else }
\end{array}\right.
$$

where interval II is handled if and only if:

$$
\frac{\mathrm{MWN}}{\rho}-\frac{\left(1-\phi_{\mathrm{p}}^{\mathrm{p}}\right)}{\phi_{\mathrm{p}}^{\mathrm{p}}}\left(\frac{\mathrm{MW}}{\rho_{\mathrm{h}}}\left(\mathrm{N}^{\mathrm{T}}-\mathrm{N}\right)\right) \geq 0
$$

$\rho$ and $\rho_{\text {homo }}$ are the monomer and polymer densities, MW the molecular weight of monomer, and $\phi_{\mathrm{p}}{ }^{\mathrm{p}}$ the volumetric fraction of polymer in the polymer particles (polymer+monomer in the particles). The value of $\phi_{\mathrm{p}}{ }^{\mathrm{p}}$ can be found in the literature for several polymers and monomers (e.g. Gilbert [15]). Therefore, the concentration of monomer in the polymer particles can directly be measured.

In the following part of this work, we treat the on-line estimation of $\mu$ and validate it experimentally. We then develop a control law to calculate the desired flow rate of monomer in order to maximize $\left[\mathrm{M}^{\mathrm{P}}\right]$, under safe conditions.

\subsection{Estimation of $\mu$}

Consider the augmented system, where the unknown dynamic of $\mu$ is represented by $\varepsilon_{\mu}$ :

$$
\begin{aligned}
& \dot{\mathrm{N}}=\mathrm{Q}-\mu\left[\mathrm{M}^{\mathrm{P}}\right] \mathrm{K}_{\mathrm{P}} \\
& \dot{\mu}=\varepsilon_{\mu}
\end{aligned}
$$

and $\left[\mathrm{M}^{\mathrm{P}}\right]$ is given by equation (7).

System (9) can be written in the following form:

$$
\begin{aligned}
& {\left[\begin{array}{c}
\dot{\mathrm{N}} \\
\dot{\mu}
\end{array}\right]=\underbrace{\left[\begin{array}{cc}
0 & -\left[\mathrm{M}^{\mathrm{P}}\right] \mathrm{K}_{\mathrm{P}} \\
0 & 0
\end{array}\right]}_{\mathrm{A}} \underbrace{\left[\begin{array}{c}
\mathrm{N} \\
\mu
\end{array}\right]}_{\mathrm{x}}+\underbrace{\left[\begin{array}{c}
\mathrm{Q} \\
0
\end{array}\right]}_{\mathrm{q}}+\left[\begin{array}{c}
0 \\
\varepsilon_{\mu}
\end{array}\right]} \\
& y=C x=\left[\begin{array}{ll}
1 & 0
\end{array}\right] x=N
\end{aligned}
$$

Under this form, we cannot directly apply the high gain observer (Gautier et al. [16,17]), since one of its limitations is that the state matrix A be positive. In order to get around this problem, we can perform a change of co-ordinates on $\mu$ by defining a new variable $s$, such that:

$$
\varsigma=-\mu
$$

The system becomes:

$$
\begin{aligned}
& {\left[\begin{array}{c}
\dot{\mathrm{N}} \\
\dot{\sigma}
\end{array}\right]=\underbrace{\left[\begin{array}{cc}
0 & {\left[\mathrm{M}^{\mathrm{P}}\right] \mathrm{K}_{\mathrm{P}}} \\
0 & 0
\end{array}\right]}_{\mathrm{A}}[\underbrace{\left[\begin{array}{c}
\mathrm{N} \\
\varsigma
\end{array}\right]}_{\mathrm{x}}+\underbrace{\left[\begin{array}{c}
\mathrm{Q} \\
0
\end{array}\right]}_{\mathrm{u}}+\left[\begin{array}{c}
0 \\
\varepsilon_{\varsigma}
\end{array}\right]} \\
& \mathrm{y}=\mathrm{Cx}=\left[\begin{array}{ll}
1 & 0
\end{array}\right] \mathrm{x}=\mathrm{N}
\end{aligned}
$$

The new system (12) is under a canonical form of observability and we can construct a high gain observer as given by the following system:

$$
\begin{aligned}
& \dot{\hat{\mathrm{N}}}=\mathrm{Q}+\left[\mathrm{M}^{\mathrm{P}}\right] \mathrm{K}_{\mathrm{P}} \hat{\boldsymbol{\zeta}}-2 \theta(\hat{\mathrm{N}}-\mathrm{N}) \\
& \dot{\hat{\mathrm{S}}}=-\frac{\theta^{2}}{\left[\mathrm{M}^{\mathrm{P}}\right] \mathrm{K}_{\mathrm{P}}}(\hat{\mathrm{N}}-\mathrm{N})
\end{aligned}
$$

This observer was tested for the homopolymerization of several monomers in a 7 liter calorimeter. The parameter $\theta$ was set to be equal to 0.01 for all runs.

In the estimator, the overall calorimetric conversion is used to estimate the number of moles of radicals in the polymer particles, $\mu$. By definition, $\mu$ contains information on the number of particles and the average number of radicals per particles, $\bar{n}$. This latter can help in the modeling and simulation of the evolution of radicals in the polymer particles (absorption, desorption and termination). $\bar{n}$ can be obtained from $\mu$, if the number of particles is known. The number of moles of radicals per particle $\bar{n}$ was determined off-line, by introducing the number of particles, determined from the measurements of the particle size. 
Conversion

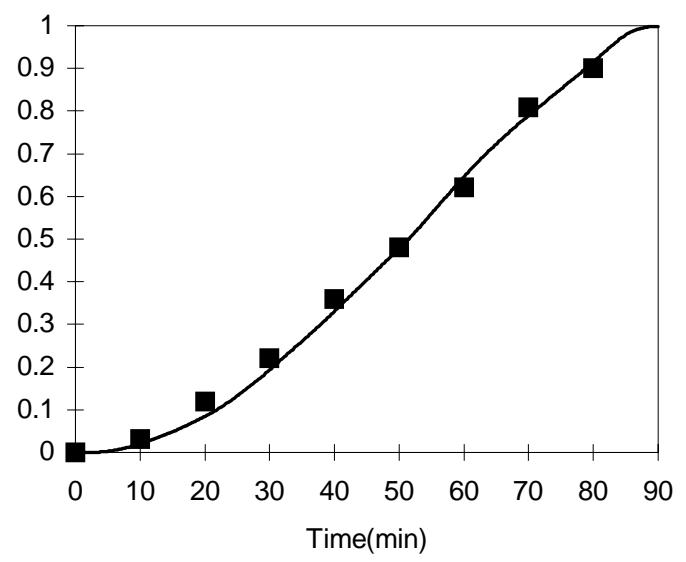

Figure 1: Overall conversion estimated by calorimetry (-) and gravimetric conversions ( $(\mathbf{})$, homopolymerization of styrene (Exp. 15).

Figure 2 shows the evolution of $\overline{\mathrm{n}}$ during the homopolymerization of styrene (recipe given in Table 1). As expected, it can be seen that $\bar{n}$ is equal to 0.5 during interval II, and increases at the end of the reaction due to the gel effect (Gilbert [15]). This demonstrates the feasibility of the approach and measurement techniques. As mentioned the number of particles is estimated based on the measurement of the particle size by QELS. The precision of the technique must be taken into account when analyzing the variations in $\mathrm{N}_{\mathrm{P}}{ }^{\mathrm{T}}$ and therefore in $\overline{\mathrm{n}}$. The precision of the estimates of $\bar{n}$ is set by accuracy of the thermocouples, and is therefore quite good. However, experience dictates that QELS measurements are only accurate to within $\pm 10 \mathrm{~nm}$. In certain circumstances, the estimates must thus be viewed accordingly.

Othman [18] obtained similar results for PVA and PMMA systems (not shown here for the sake of brevity). In both of these cases, the value of $\bar{n}$ increased at high conversions to levels found in the literature and offline gravimetric measurements confirmed the accuracy of the calorimetric measurements. Given these results, we can be satisfied that our calorimetric observer functions correctly and is well tuned.
Total number of particles

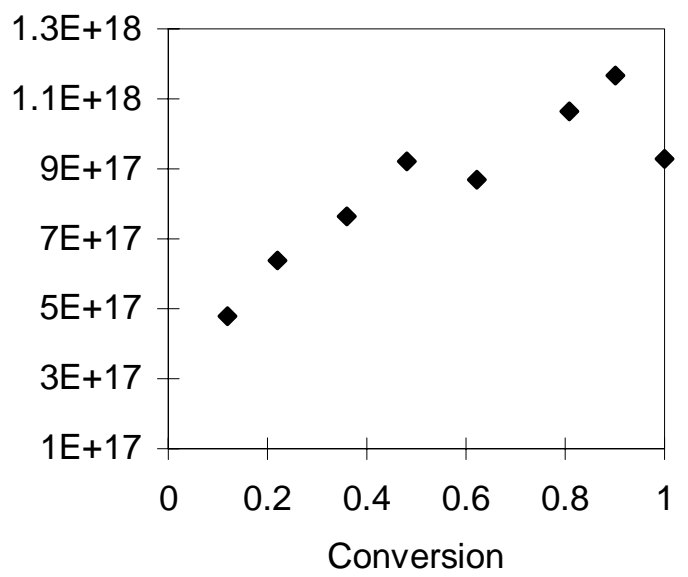

Average number of radicals per particle

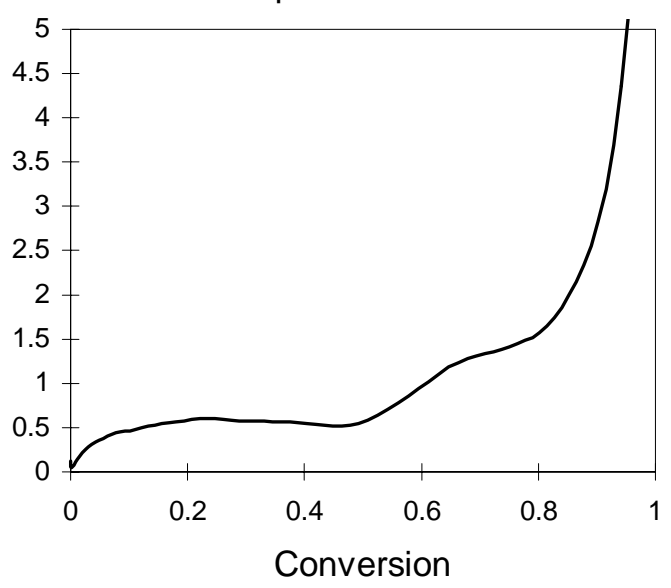

Figure 2: Total number of particles, up, and the estimated $\bar{n}$, down, homopolymerization of styrene (Exp. 15).

\subsection{Control of $\left[M^{p}\right]$}

The manipulated variable that allows us to control the concentration of monomer in the polymer particles is Q. Since the overall conversion is obtained on-line by calorimetry, we can take $\mathrm{N}$ as the system output. We can therefore write a control law that minimizes the error between the desired and real values of N. Since the reaction rate $R_{P}$ is nonlinear, we propose to use a nonlinear geometric control law with input/output linearization, Isidori [19].

Consider the material balance, 


$$
\begin{aligned}
& \dot{\mathrm{N}}=\underbrace{\mathrm{Q}}_{\substack{\mathrm{u} \\
\mathrm{Q}}} \underbrace{\mathrm{N}}_{\mathrm{f}} \mathrm{R}_{\mathrm{P}}^{\mathrm{R}}
\end{aligned}
$$

Before calculating a transformation that renders the input/output comportment linear, we check if the relative order is equal to one, as defined by Isidory [19]. For $\mathrm{r}=1$, we calculate $<\mathrm{dh}_{,} \mathrm{ad}_{\mathrm{f}}^{\mathrm{r}-1}(\mathrm{~g})>$ :

$$
\begin{aligned}
\mathrm{L}_{\mathrm{f}} \mathrm{h} & =\frac{\partial \mathrm{h}}{\partial \mathrm{x}} \mathrm{f} \\
& =-\mathrm{R}_{\mathrm{P}} \neq 0
\end{aligned}
$$

Therefore, the relative order of the system $r=1$. This allows us to apply the following transformation :

$$
\begin{aligned}
\mathrm{v} & =\Omega(\mathrm{x}, \mathrm{u})=\sum_{\mathrm{k}=0}^{1} \beta_{\mathrm{k}} \mathrm{L}_{\mathrm{f}}^{\mathrm{k}} \mathrm{h}+(-1)^{0} \beta_{1}<\mathrm{dh}_{,} \mathrm{ad}_{\mathrm{f}}^{0}(\mathrm{~g})>\mathrm{u} \\
& =\beta_{0} \mathrm{~N}_{1}+\beta_{1}\left(-\mathrm{R}_{\mathrm{P} 1}\right)+\beta_{1} \mathrm{u}
\end{aligned}
$$

which implies :

$$
\mathrm{u}=\frac{\mathrm{v}-\beta_{0} \mathrm{~N}+\beta_{1} \mathrm{R}_{\mathrm{P}}}{\beta_{1}}
$$

We can use a linear $\mathrm{P}$ loop as an external input:

$$
v-\beta_{0} N=\kappa_{p} \underbrace{\left(y^{d}-y\right)}_{\varepsilon}
$$

Therefore,

$$
\mathrm{u}=\mathrm{Q}=\frac{\kappa_{\mathrm{p}}}{\beta_{1}} \varepsilon+\mathrm{R}_{\mathrm{P}}
$$

where the value of the gain $\kappa_{\mathrm{p}} / \beta_{1}$ was chosen to be equal to 0.01 as a compromise between rapidity of convergence and avoiding oscillations.

The desired output, $\mathrm{y}^{\mathrm{d}}=\mathrm{N}^{\mathrm{d}}$ is calculated as a function of the maximum polymer saturation with monomer. The saturation condition is given by equation 7 . The value of $\mathrm{N}^{\mathrm{d}}$ that maintains the polymer particles at the saturation value, without an excess of monomer, is therefore:

$$
\mathrm{N}^{\mathrm{d}}=\frac{\mathrm{N}^{\mathrm{T}} / \rho_{\mathrm{h}}}{\left(\frac{1}{\rho} \frac{\phi_{\mathrm{p}}^{\mathrm{p}}}{\left(1-\phi_{\mathrm{p}}^{\mathrm{p}}\right)}+\frac{1}{\rho_{\mathrm{h}}}\right)}
$$

The control strategy was experimentally tested during styrene homopolymerization (recipe shown in Table 2). The objective was to maintain $\left[\mathrm{M}_{\mathrm{P}}\right]$ at $0.5 \times\left[\mathrm{M}_{\mathrm{P}}\right]^{\mathrm{sat}}$, once the nucleation (particle formation) stage is finished.
Figures $7 \mathrm{a}$ and $\mathrm{b}$ show the monomer conversion and the heat produced by the homopolymerization of styrene. The initial charge of monomer was allowed to react until we reach $50 \%$ of $\left[\mathrm{M}_{\mathrm{P}}\right]^{\text {sat }}$. At this moment (15 minutes) we began to feed monomer to system. It can be seen that the conversion was maintained almost constant during the semi-continuous portion of the experiment.

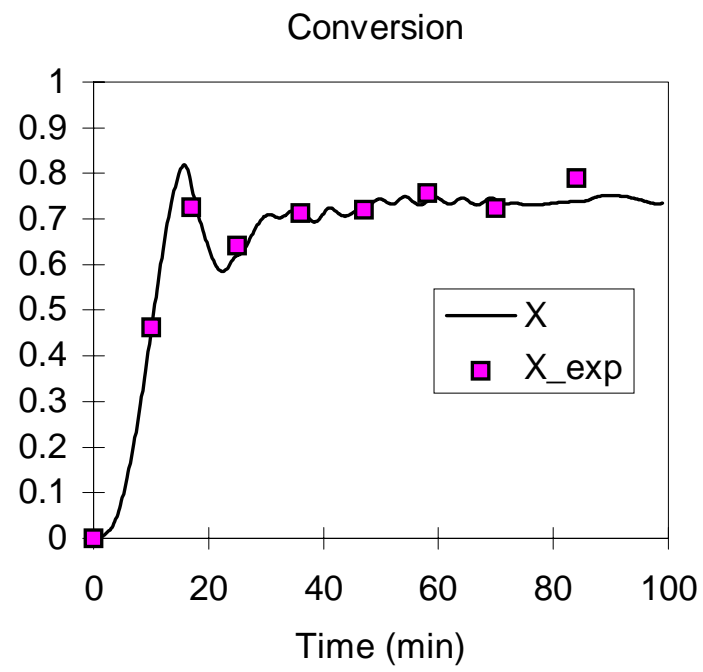

Figure 7a: Experiment C32. Estimated conversion by calorimetry.

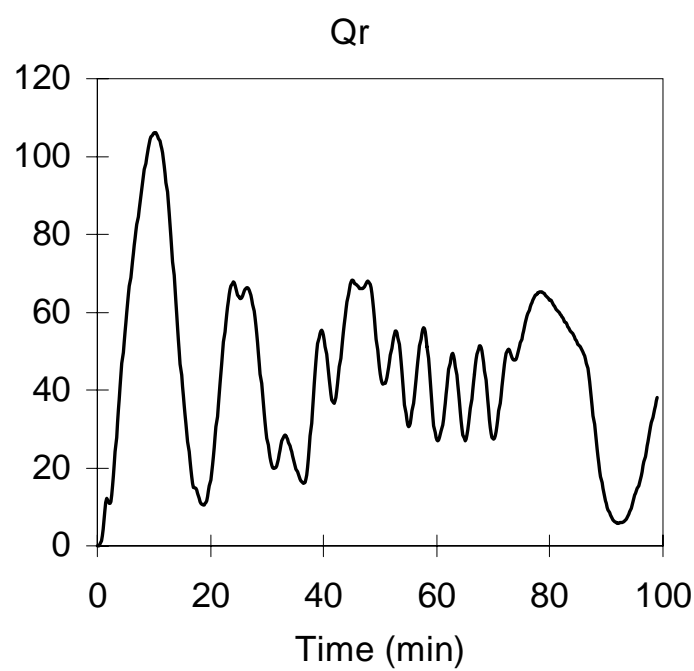

Figure 7b: C32. Heat produced by the reaction (W), obtained by calorimetry.

Figure 7b shows that $\mathrm{Q}_{\mathrm{R}}$ oscillates during the semi-continuous part of the reaction. These oscillations are due to the oscillations in the concentration of monomer in the polymer particles. Figure 7c shows that at the beginning of the reaction $\left[M_{P}\right]$ equals the saturation value for about 
10 minutes. When the value of $\left[\mathrm{M}_{\mathrm{P}}\right]$ starts to be lower than the set-point, the controller is activated. The controller takes a little of time to stabilize at the set-point because of the oscillations in the estimation of the monomer conversion at the beginning of the reaction. Thereafter, it can be seen that the concentration of monomer in the polymer particles is maintained at the set-point, with small oscillations that are due to the calorimetric optimization technique.

The calorimetric estimations use values of the heat transfer coefficient (between the jacket and the reactor) and the heat loss obtained by initial calibration. Since these values change as a function of the viscosity of the reaction medium, we frequently introduce gravimetric measurements to take into account the change of the reaction medium. However, during the 15 first minutes of the reaction, no gravimetric measurements were available (introduced with 5 minutes delay) whereas an important change in the reaction medium occurred after particle formation. This distorts the calorimetric estimates. Since, the control strategy acts as a function of the calorimetric estimates that are corrected continuously, this causes oscillations in the control especially at the beginning of the reaction.

Concentration of monomer in the polymer particles

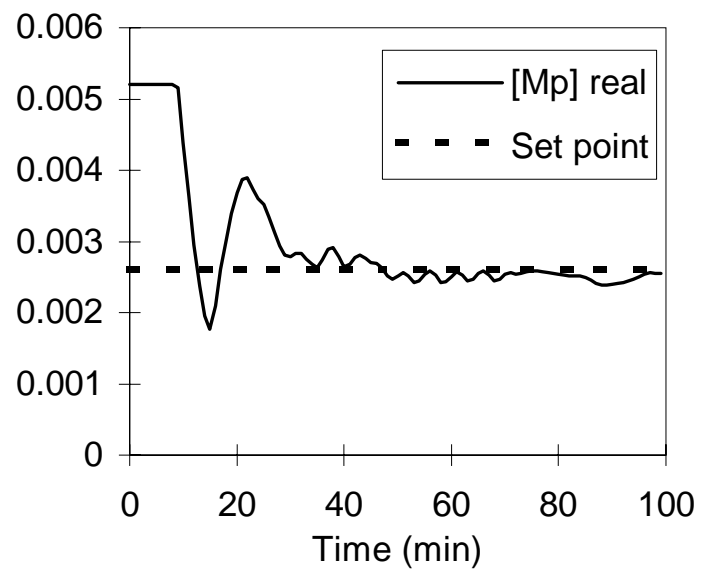

Figure 7c: Experiment C32. $\left[\mathrm{M}_{\mathrm{P}}\right]\left(\mathrm{mol} / \mathrm{cm}^{3}\right)$.

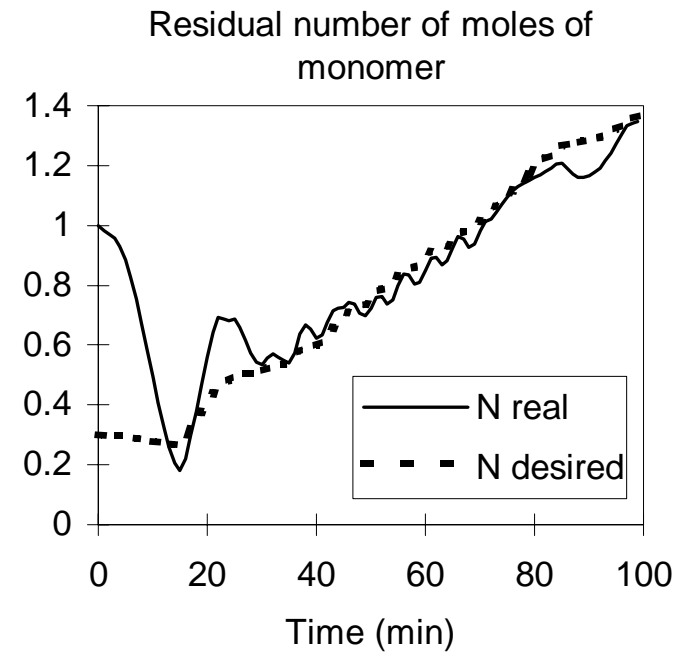

Figure 7d: Experiment C32. Real and desired number of moles of monomers.

\section{Copolymerization processes}

The material balance of a copolymerization process is given by system 20 . We suppose that $\mathrm{N}_{1}$, $\mathrm{N}_{2}$ and $\mu$ are estimated on-line Othman 2000).

Two coupled control laws must be applied simultaneously in order to control copolymerization processes. The first objective will be to control the concentration of monomer in the polymer particles $\left[\mathrm{M}^{\mathrm{p}}\right]$. The flow rate of the less reactive monomer $\left(\mathrm{Q}_{2}\right)$ will be used for this purpose (where the reactivity of monomers is determined by the reactivity ratios and the propagation constants). Then, the flow rate of the most reactive monomer $\left(\mathrm{Q}_{1}\right)$ will be used to control the polymer composition by maintaining $\left(\mathrm{N}_{1} / \mathrm{N}_{2}\right)$ at $\left(\mathrm{N}_{1} / \mathrm{N}_{2}\right)^{\mathrm{d}}$. The sum of $\mathrm{Q}_{1}$ and $\mathrm{Q}_{2}$ must not allow $\left[\mathrm{M}^{\mathrm{P}}\right]$ to exceed $\left[\mathrm{M}^{\mathrm{P}}\right]^{\text {desired }}$.

In order to control $\mathrm{N}_{1}$ we use the following system assuming the output $\mathrm{y}=\mathrm{N}_{1}$ that will be used in the controller:

$$
\begin{aligned}
& \dot{\mathrm{x}}=\left[\begin{array}{c}
\dot{\mathrm{N}}_{1} \\
\dot{\mathrm{N}}_{2}
\end{array}\right]=\underbrace{\left[\begin{array}{c}
-\mathrm{R}_{\mathrm{P} 1} \\
\mathrm{Q}_{2}-\mathrm{R}_{\mathrm{P} 2}
\end{array}\right]}_{\mathrm{f}(\mathrm{x})}+\underbrace{[\begin{array}{c}
1 \\
0
\end{array} \underbrace{\mathrm{Q}_{1}}_{\mathrm{u}}}_{\mathrm{g}(\mathrm{x})} \\
& y=\underbrace{N_{1}}
\end{aligned}
$$

System given by 20 is a nonlinear single input single output system with the states $\mathrm{x}, \mathrm{u}$ is the manipulated input and $y$ the model output. $\mathrm{Q}_{2}$ is 
not considered as a manipulated variable, but assumed to be a known input. In order to test the controllability of the system and whether or not $u$ can be used to control $\mathrm{N}_{1}$, we first calculate the relative order:

$$
\begin{aligned}
\mathrm{L}_{\mathrm{f}} \mathrm{h} & =\frac{\partial \mathrm{h}_{\mathrm{f}}}{\mathrm{x}} \\
& =\left[\begin{array}{ll}
1 & 0
\end{array}\right]\left[\begin{array}{c}
-\mathrm{R}_{\mathrm{P} 1} \\
\mathrm{Q}_{2}-\mathrm{R}_{\mathrm{P} 2}
\end{array}\right] \\
& =-\mathrm{R}_{\mathrm{P} 1} \neq 0
\end{aligned}
$$

The relative order of the system $r$ is equal to one and we can therefore calculate a nonlinear input/output linearizing controller. In order to do so, we define the following state feedback transformation (Kravaris et al. [20]):

$$
\begin{aligned}
\mathrm{v} & =\Omega(\mathrm{x}, \mathrm{u})=\sum_{\mathrm{k}=0}^{1} \beta_{\mathrm{k}} \mathrm{L}_{\mathrm{f}}^{\mathrm{k}} \mathrm{h}+(-1)^{0} \beta_{1}<\mathrm{dh}, \mathrm{ad}_{\mathrm{f}}^{0}(\mathrm{~g})>\mathrm{u} \\
& =\beta_{0} \mathrm{~h}+\beta_{1} \frac{\partial \mathrm{h}_{1}}{\partial \mathrm{x}}+\beta_{1} \frac{\partial \mathrm{h}}{\partial \mathrm{x}} \mathrm{g} \\
& =\beta_{0} \mathrm{~N}_{1}+\beta_{1}\left(-\mathrm{R}_{\mathrm{P} 1}\right)+\beta_{1} \mathrm{u}
\end{aligned}
$$

and we can therefore calculate the input $\mathrm{u}$ :

$$
\begin{aligned}
\mathrm{u} & =\frac{\mathrm{v}-\beta_{0} \mathrm{~N}_{1}+\beta_{1} \mathrm{R}_{\mathrm{P} 1}}{\beta_{1}} \\
& =\frac{\mathrm{v}}{\beta_{1}}-\frac{\beta_{0}}{\beta_{1}} \mathrm{~N}_{1}+\mathrm{R}_{\mathrm{P} 1}
\end{aligned}
$$

where $u$ is in $\mathrm{mol} / \mathrm{s}$. The external input $v$ can be used to add a linear PI loop, as follows:

$$
\mathrm{v}-\beta_{0} \mathrm{~N}_{1}=\kappa_{\mathrm{P}} \underbrace{\left(\mathrm{y}^{\mathrm{d}}-\mathrm{y}\right)}_{\varepsilon}+\frac{1}{\tau_{\mathrm{I}}} \int_{0}^{\mathrm{t}_{\mathrm{f}}}\left(\mathrm{y}^{\mathrm{d}}-\mathrm{y}\right) \mathrm{dt}
$$

Hence, the complete control variable becomes:

$$
\mathrm{u}=\mathrm{Q}_{1}=\frac{1}{\beta_{1}}\left(\kappa_{\mathrm{P}} \varepsilon+\frac{1}{\tau_{\mathrm{I}}} \int_{0}^{\mathrm{t}_{\mathrm{f}}} \varepsilon \mathrm{dt}\right)+\mathrm{R}_{\mathrm{P} 1}
$$

Without any loss of generality, we can take $\beta_{1}=1$. Note that the other state of the model $\left(\mathrm{N}_{2}\right)$ is stable for all values of $\mathrm{Q}_{1}$. $\mathrm{N}_{2}$ decreases if all of monomer 2 is added to the reactor at $t=0$, or it can depend on $\mathrm{Q}_{2}$, where $\mathrm{Q}_{2}$ must be set at some reasonable rate. The proportional gain must be chosen in a way that guarantees stable and rapid convergence to the desired composition. Equation 25 allows us to calculate the flow rate of the more reactive monomer in order to track the polymer composition. In order to calculate the flow rate of the less reactive monomer $\mathrm{Q}_{2}$, we consider the copolymerization material balance, with the control output $\mathrm{N}_{2}$ :

$$
\begin{aligned}
& \dot{\mathrm{x}}=\left[\begin{array}{c}
\dot{\mathrm{N}}_{1} \\
\dot{\mathrm{N}}_{2}
\end{array}\right]=\underbrace{\left[\begin{array}{c}
\mathrm{Q}_{1}-\mathrm{R}_{\mathrm{P} 1} \\
-\mathrm{R}_{\mathrm{P} 2}
\end{array}\right]}_{\mathrm{f}(\mathrm{x})}+\underbrace{[\begin{array}{c}
0 \\
1
\end{array} \underbrace{\mathrm{Q}_{2}}_{\mathrm{u}}}_{\mathrm{g}(\mathrm{x})} \\
& \mathrm{y}=\underbrace{\mathrm{N}_{2}}_{\mathrm{N}(\mathrm{x})}
\end{aligned}
$$

We calculate the desired $\mathrm{N}_{2}$ needed to maintain $\left[\mathrm{M}^{\mathrm{p}}\right]$ at the set-point, here (arbitrarily) taken to be $\left[\mathrm{M}^{\mathrm{P}}\right]^{\text {sat }}$. The polymer particles are saturated with monomer if the volume of free monomer is superior or equal to the desired volume of monomer required to saturate the polymer particles, represented by the following equation:

$$
\alpha \mathrm{N}_{1}+\beta \mathrm{N}_{2} \geq \gamma
$$

with:

$$
\begin{aligned}
& \alpha=\frac{\mathrm{MW}_{1}}{\rho_{1}}+\frac{\mathrm{MW}_{1}\left(1-\phi_{\mathrm{p}}^{\mathrm{p}}\right)}{\rho_{1, \mathrm{~h}} \phi_{\mathrm{p}}^{\mathrm{p}}} \\
& \beta=\frac{\mathrm{MW}_{2}}{\rho_{2}}+\frac{\mathrm{MW}_{2}\left(1-\phi_{\mathrm{p}}^{\mathrm{p}}\right)}{\rho_{2, \mathrm{~h}} \phi_{\mathrm{p}}^{\mathrm{p}}} \\
& \gamma=\frac{\left(1-\phi_{\mathrm{p}}^{\mathrm{p}}\right)}{\phi_{\mathrm{p}}^{\mathrm{p}}}\left(\frac{\mathrm{MW}_{1} \mathrm{~N}_{1}^{\mathrm{T}}}{\rho_{1, \mathrm{~h}}}+\frac{\mathrm{MW}_{2} \mathrm{~N}_{2}^{\mathrm{T}}}{\rho_{2, \mathrm{~h}}}\right)
\end{aligned}
$$

The desired number of moles of the less reactive monomer $\left(\mathrm{N}_{2}{ }^{\mathrm{d}}\right)$ is therefore given by the following equation:

$$
\mathrm{N}_{2}^{\mathrm{d}}=\frac{\gamma}{\alpha\left(\frac{\mathrm{N}_{1}}{\mathrm{~N}_{2}}\right)^{\mathrm{d}}+\beta}
$$

By introducing $\left(\mathrm{N}_{1} / \mathrm{N}_{2}\right)^{\mathrm{d}}$, this relation ensures that the polymer particle be saturated, and that no excess of monomer be introduced. The flow rate $\mathrm{Q}_{2}$ is calculated in a way such that $\mathrm{Q}_{1}+\mathrm{Q}_{2}$ bring $\left[\mathrm{M}^{\mathrm{P}}\right]$ to the saturation value. This allows us to simultaneously maintain $\mathrm{N}_{1} / \mathrm{N}_{2}$ at the desired value. Controlling $\left[\mathrm{M}^{\mathrm{P}}\right]$ is therefore not decoupled from the composition control law.

We construct a control law that minimizes the error between $\mathrm{N}_{2}$ and $\mathrm{y}^{\mathrm{d}}=\mathrm{N}_{2}{ }^{\mathrm{d}}$. The relative order is $\mathrm{r}=1$ since $<\mathrm{dh}_{\mathrm{ad}}^{\mathrm{r}-1}(\mathrm{~g})>$ gives $\mathrm{R}_{\mathrm{P} 2} \neq 0$. We can calculate an input/output linearizing transformation, and this gives:

$$
\mathrm{u}=\frac{\mathrm{v}-\beta_{0} \mathrm{~N}_{2}+\beta_{1} \mathrm{R}_{\mathrm{P} 2}}{\beta_{1}}
$$


We can use a linear P loop as an external input $v$, therefore,

$$
\mathrm{u}=\mathrm{Q}_{2}=\frac{\kappa_{\mathrm{p}}}{\beta_{1}} \varepsilon+\mathrm{R}_{\mathrm{P} 2}
$$

where the parameters were adjusted as in the case of homopolymerization ( $\kappa_{\mathrm{p}}=.01, \beta_{0}=0$ and $\beta_{1}=1$ ).

We will consider the pair MMA-BuA to validate the controllers. A small amount of each monomer is charged at the beginning of the reaction. Table 3 gives the recipe used to test the controllers. Since MMA is the more reactive of the two monomers, its flow rate is used to control the copolymer composition, and the flow rate of $\mathrm{BuA}$ is used to control $\left[\mathrm{M}^{\mathrm{P}}\right]$. Two flow streams are necessary. In one of them, the required amount of surfactant needed to maintain stable emulsions is added creating thereby a "preemulsion". In the second flow stream, we simply introduce the required amount of pure monomer.

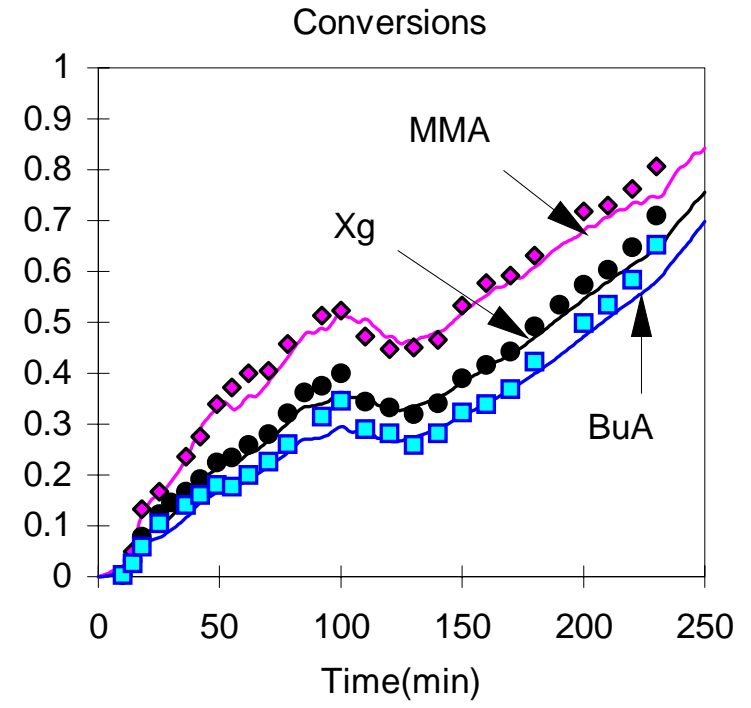

Figure 8: Experiment C19: Overall and individual conversions. Experimental measurements, represented by the discontinuous points, are obtained by GC.

Figure 8 shows the instantaneous overall conversions obtained by calorimetry. The measured conversion is then used in the nonlinear high gain observer (Othman [18]) to estimate the evolution of the number of moles of each monomer, and the individual conversions, Figure 8. These estimations are in good agreement with the independent experimental GC measurements done off-line (after the experiment). The decrease in the overall conversion is due to the addition of
$\mathrm{BuA}$ at a high flow rate in order to maintain the concentration of monomer in the polymer particles under saturation conditions for an hour (between 70 and 130 minutes).
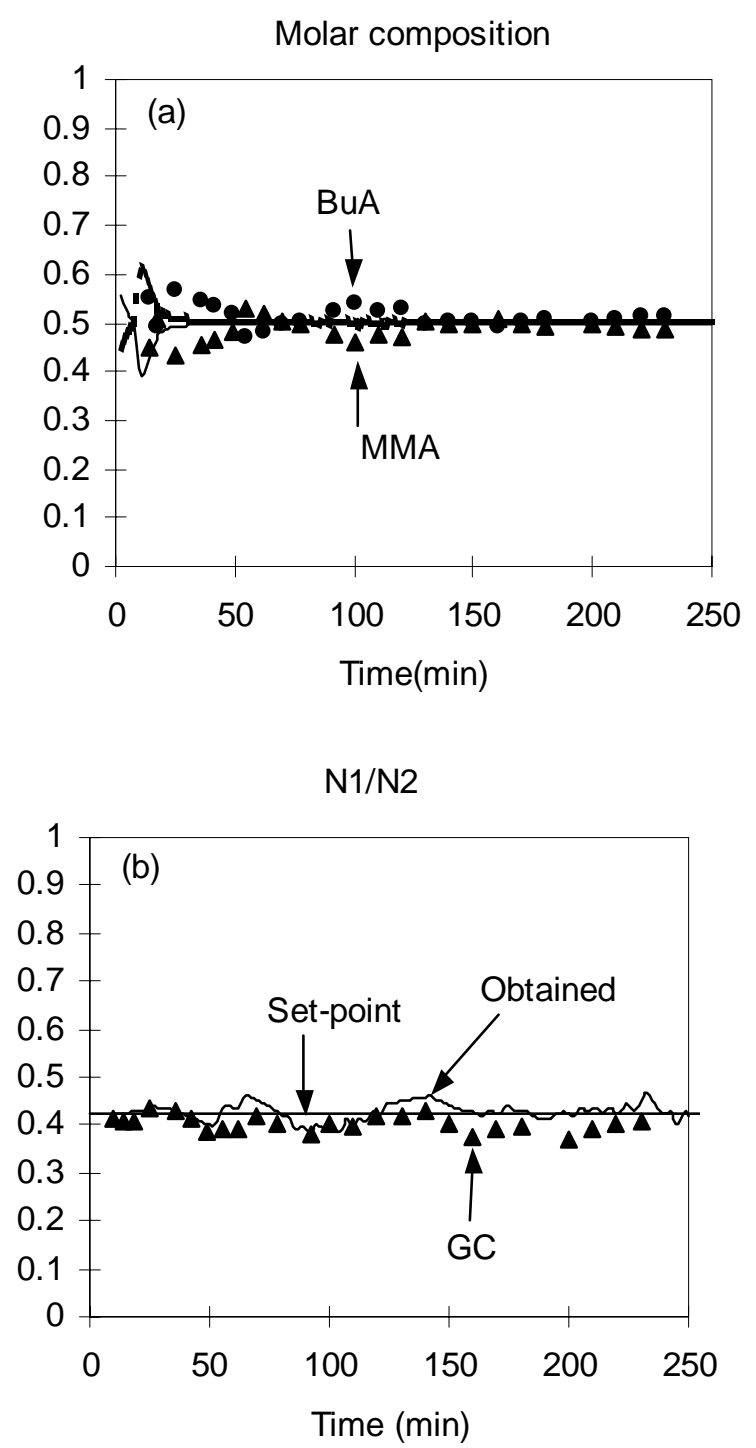

Figure 9: (a) Experiment C19: Cumulative molar fractions of each homopolymer in the copolymer, and (b) the molar monomers ratio.

Figure 9 shows the obtained copolymer composition, and the obtained $\left(\mathrm{N}_{1} / \mathrm{N}_{2}\right)$. The composition controller minimizes the error between $\left(\mathrm{N}_{1} / \mathrm{N}_{2}\right)$ and $\left(\mathrm{N}_{1} / \mathrm{N}_{2}\right)^{\mathrm{d}}$, that is calculated as a function of the reactivities of the involved monomers. It can be seen that both the monomer ratio and the copolymer composition are in good agreement with the set-point. The experimental values on the figures are obtained by GC as well.

The concentration of monomer in the polymer particles can be determined from the estimated 
number of moles of free monomer in the reactor. Figure 10 shows the total monomer concentration in polymer particles and the total number of moles of $\mathrm{BuA}$. It can be seen that during interval II, where the polymer particles are saturated with monomer (due to an important initial charge), $\mathrm{N}_{2}{ }^{\mathrm{T}}$ is therefore constant $\left(\mathrm{Q}_{2}=0\right)$. When the monomer concentration in polymer particles starts to decrease, $\mathrm{N}_{2}{ }^{\mathrm{T}}$ increases (for one hour) and brings the monomer concentration back to the saturation value. At 130 minutes, we voluntarily stop the addition of $\mathrm{BuA}$ in order to consume the added monomers. As $\mathrm{Q}_{2}$ goes back to zero, the concentration of monomer in polymer particles decreases with conversion. The period of simultaneous control was voluntarily shortened in order to avoid overfilling the reactor and to minimize the reaction time. It should be noted that this period could have lasted much longer.

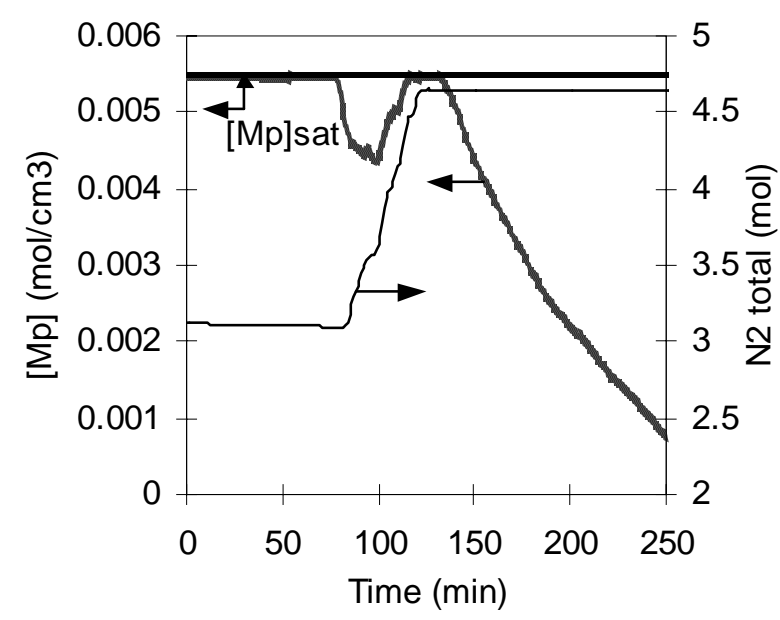

Figure 10: Experiment C19: The concentration of monomer in the polymer particles, the maximum saturation concentration, and the total number of moles of $\mathrm{BuA}$ versus time.

We have seen that both control laws (composition and reaction rate) are coupled, and that this approach allows us to satisfy both of the control objectives at the same time. An important physical constraint to take into consideration is the maximum possible flow rate (limited by the pumps). $\mathrm{Q}_{2}$ and $\mathrm{Q}_{1}$ must be of the same order, otherwise, the composition controller might take a lot of time to compensate the addition of $\mathrm{Q}_{2}$ and to bring the monomer ratio back to the set-point, which might affect the polymer composition.

\section{Terpolymerisation processes}

We will initially consider polymer composition control with the manipulated variables $\mathrm{Q}_{1}$ and $\mathrm{Q}_{2}$, the two most reactive monomers. The terpolymerization model of hydrophobic monomers is given by the following system:

$$
\begin{aligned}
& \dot{\mathrm{x}}=\left[\begin{array}{c}
\dot{\mathrm{N}}_{1} \\
\dot{\mathrm{N}}_{2} \\
\dot{\mathrm{N}}_{3}
\end{array}\right]=\underbrace{\left[\begin{array}{c}
-\mathrm{R}_{\mathrm{P} 1} \\
-\mathrm{R}_{\mathrm{P} 2} \\
\mathrm{Q}_{3}-\mathrm{R}_{\mathrm{P} 3}
\end{array}\right]}_{\mathrm{f}(\mathrm{x})}+\underbrace{\left[\begin{array}{c}
1 \\
0 \\
0
\end{array}\right] \underbrace{\mathrm{u}_{1}}_{\mathrm{g}_{2}}+\underbrace{\left[\begin{array}{c}
0 \\
1 \\
0
\end{array}\right] \underbrace{\mathrm{Q}_{2}}_{\mathrm{u}_{2}}}_{\mathrm{x})}}_{\mathrm{g}_{1}(\mathrm{x})} \\
& \mathrm{y}=\left[\begin{array}{c}
\mathrm{h}_{1} \\
\mathrm{~h}_{2}
\end{array}\right]=\underbrace{\left[\begin{array}{c}
\mathrm{N}_{1} \\
\mathrm{~N}_{2}
\end{array}\right]}_{\mathrm{h}(\mathrm{x})}
\end{aligned}
$$

where $\mathrm{N}_{1}$ and $\mathrm{N}_{2}$ are taken to be the outputs of the model. It is supposed that all $\mathrm{N}_{\mathrm{i}}$ values are available on-line.

In order to guarantee the controllability of system 31, the characteristic matrix must be nonsingular and the relative orders equal to one. The characteristic matrix corresponding to the system 31 is:

$$
C(x)=\left[\begin{array}{cc}
L_{g_{1}} h_{1} & L_{g_{2}} h_{1} \\
L_{g_{1}} h_{2} & L_{g_{2}} h_{2}
\end{array}\right]=\left[\begin{array}{ll}
1 & 0 \\
0 & 1
\end{array}\right]
$$

and is therefore nonsingular. The relative orders $\mathrm{r}_{1}=1$ and $\mathrm{r}_{2}=1$.

We can therefore realize two input/output linearizing transformations, correlating $\mathrm{Q}_{1}$ with $\mathrm{N}_{1}$ and $\mathrm{Q}_{2}$ with $\mathrm{N}_{2}$ :

$$
\begin{aligned}
\mathrm{v}_{1} & =\Omega_{1}(\mathrm{x}, \mathrm{u})=\sum_{\mathrm{k}=0}^{1} \beta_{\mathrm{k} 0} \mathrm{~L}_{\mathrm{f}}^{\mathrm{k}} \mathrm{h}_{1}+(-1)^{0} \beta_{10}<\mathrm{dh}_{1}, \mathrm{ad}_{\mathrm{f}}^{0}\left(\mathrm{~g}_{1}\right)>\mathrm{u} \\
& =\beta_{00} \mathrm{~h}_{1}+\beta_{10} \frac{\partial \mathrm{h}_{1}}{\partial \mathrm{x}} \mathrm{f}+\beta_{10} \frac{\partial \mathrm{h}_{1}}{\partial \mathrm{x}} \mathrm{g}_{1} \\
& =\beta_{00} \mathrm{~N}_{1}+\beta_{10}\left(-\mathrm{R}_{\mathrm{P} 1}\right)+\beta_{10} \mathrm{u}_{1}
\end{aligned}
$$

By doing the same transformation for input $\mathrm{u}_{2}$ and replacing the external input $v_{1}$ by the set-point of $\mathrm{N}_{1}$, we obtain the following inputs:

$$
\begin{aligned}
& \mathrm{u}_{1}=\mathrm{Q}_{1}=\frac{\kappa_{\mathrm{P} 1}}{\beta_{10}} \varepsilon_{1}+\mathrm{R}_{\mathrm{P} 1} \\
& \mathrm{u}_{2}=\mathrm{Q}_{2}=\frac{\kappa_{\mathrm{P} 2}}{\beta_{11}} \varepsilon_{2}+\mathrm{R}_{\mathrm{P} 2}
\end{aligned}
$$

where $u_{i}$ is in mol/s. The values of $\kappa_{\mathrm{P} 1}$, and $\kappa_{\mathrm{P} 2}$ are taken to be 0.01 as in the previous systems. 
In order to control $\left[\mathrm{M}^{\mathrm{P}}\right]$, we consider the terpolymerization material balance with the output $\mathrm{N}_{3}$ and the manipulated input $\mathrm{Q}_{3}$, the flow rate of the less reactive monomer:

$$
\begin{aligned}
& \dot{\mathrm{x}}=\left[\begin{array}{c}
\dot{\mathrm{N}}_{1} \\
\dot{\mathrm{N}}_{2} \\
\dot{\mathrm{N}}_{3}
\end{array}\right]=\underbrace{\left[\begin{array}{c}
\mathrm{Q}_{1}-\mathrm{R}_{\mathrm{P} 1} \\
\mathrm{Q}_{2}-\mathrm{R}_{\mathrm{P} 2} \\
-\mathrm{R}_{\mathrm{P} 3}
\end{array}\right]}_{\mathrm{f}(\mathrm{x})}+\underbrace{\left[\begin{array}{c}
0 \\
0 \\
1
\end{array}\right]}_{\mathrm{g}(\mathrm{x})} \underbrace{\mathrm{Q}_{3}}_{\mathrm{h}(\mathrm{x})} \mathrm{u}
\end{aligned}
$$

We first calculate $\mathrm{N}_{3}{ }^{\mathrm{d}}$ that satisfies saturation conditions and then we develop the control law. Once again, we arbitrarily chose a set point where the polymer particles are exactly saturated, with no excess monomer found in the form of monomer droplets, if the following condition is valid:

$$
\mathrm{N}_{1} \delta_{1}+\mathrm{N}_{2} \delta_{2}+\mathrm{N}_{3} \delta_{3}=\frac{\left(1-\phi_{\mathrm{p}}^{\mathrm{p}}\right)}{\phi_{\mathrm{p}}^{\mathrm{p}}} \sigma
$$

where :

$$
\delta_{i}=M W_{i}\left(\frac{1}{\rho_{i}}+\frac{\left(1-\phi_{p}^{p}\right)}{\rho_{i, h} \phi_{p}^{p}}\right), i=1,2,3
$$

and

$$
\sigma=\sum_{j=1}^{3} \frac{M_{j} N_{j}^{T}}{\rho_{2, h}}
$$

Therefore, the $\mathrm{N}_{3}{ }^{\mathrm{d}}$ is directly calculated, and is given by:

$$
\mathrm{N}_{3}^{\mathrm{d}}=\frac{\left(\frac{1-\phi_{\mathrm{p}}^{\mathrm{p}}}{\phi_{\mathrm{p}}^{\mathrm{p}}}\right) \sigma}{\left(\delta_{1}\left(\frac{\mathrm{N}_{1}}{\mathrm{~N}_{3}}\right)^{\mathrm{d}}+\delta_{2}\left(\frac{\mathrm{N}_{2}}{\mathrm{~N}_{3}}\right)^{\mathrm{d}}+\delta_{3}\right)}
$$

We can then develop an input/output linearizing control law that calculates $\mathrm{Q}_{3}$ to arrive at $\mathrm{y}^{\mathrm{d}}$. The relative order of the system equals one since:

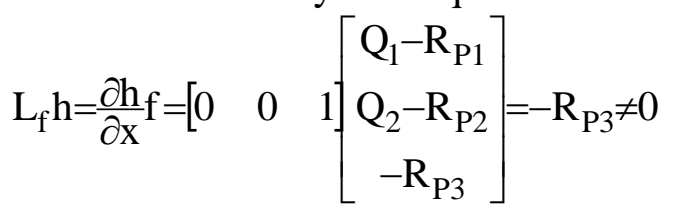

We can then construct the following input/output linearizing controller:

$$
\mathrm{u}=\frac{\kappa_{\mathrm{P}}}{\beta_{1}}(\mathrm{y}-\mathrm{d})+\mathrm{R}_{\mathrm{P} 3}
$$

where $\kappa_{\mathrm{p}}=0.01$, and $\beta_{1}=1$.

In order to validate the control law, a terpolymerization experiment (MMA-BuA-VAc) was carried out, non zero amounts of each monomer charged at the beginning of the reaction. Thereafter, the two more reactive monomers (MMA, BuA) are added at a controlled flow rate that ensures the production of a constant terpolymer composition. It is possible to introduce both MMA and $\mathrm{BuA}$ at the same flow rate in order to maintain the ratios $\left(\mathrm{N}_{1} / \mathrm{N}_{3}\right)$ and $\left(\mathrm{N}_{1} / \mathrm{N}_{3}\right)$ at the desired levels. The desired amount of VAc (the less reactive) is added at a flow rate that maintains $\left[\mathrm{M}^{\mathrm{P}}\right]$ at $\left[\mathrm{M}^{\mathrm{P}}\right]^{\text {sat }}$. The recipe used for this terpolymerization experiment is shown in Table 4.

Figure 11 shows the evolution of the overall and individual conversions of MMA, BuA and VAc.

\section{Conversions}

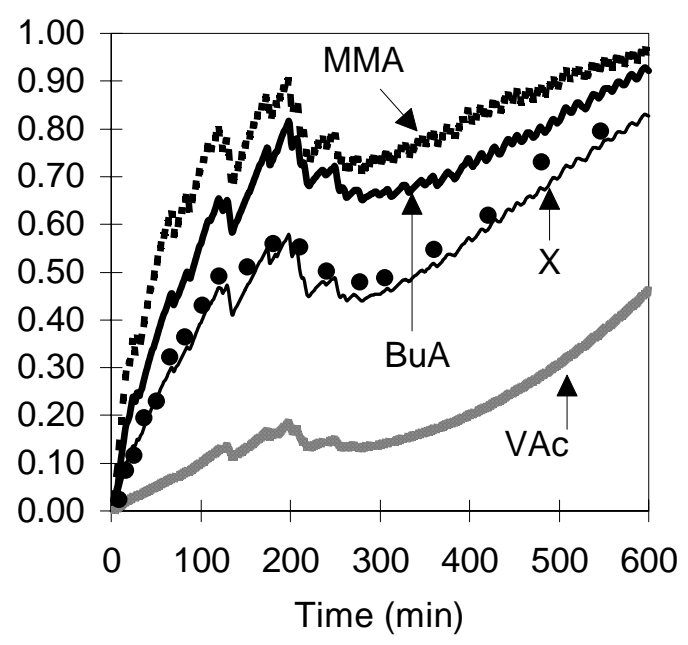

Figure 11 : C29, Overall and individual conversions.

The initial amount of monomers was sufficient to maintain saturation conditions for about 120 minutes. During this time, the flow rate of VAc, $\mathrm{Q}_{3}$, was equal to zero. When $\left[\mathrm{M}^{\mathrm{P}}\right]$ dropped below the saturation value, $\mathrm{Q}_{3}$ is activated to bring $\left[\mathrm{M}^{\mathrm{P}}\right]$ back to the set-point. 
Concentration of monomer in polymer particles

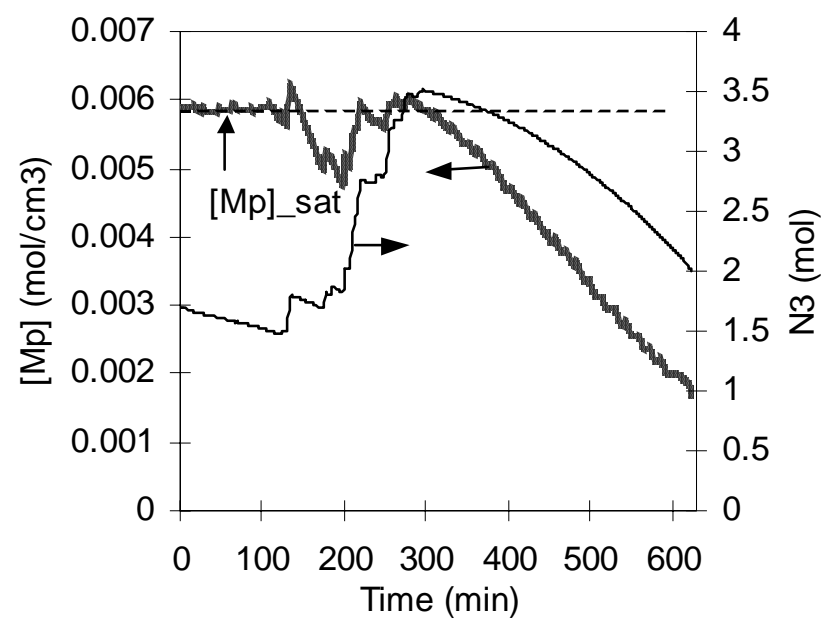

Figure 12: C29, Number of moles of the monomer the less reactive, and the concentration of monomers in the polymer particles, $\left[\mathrm{M}^{\mathrm{P}}\right]$.

In the case of this experiment, the composition controller was maintained active until the end of the reaction, and therefore the flow rate of the most reactive monomers was positive. However, the control of the concentration of monomer in the polymer particles was activated only between 120 and 300 minutes in order to decrease the reaction time.

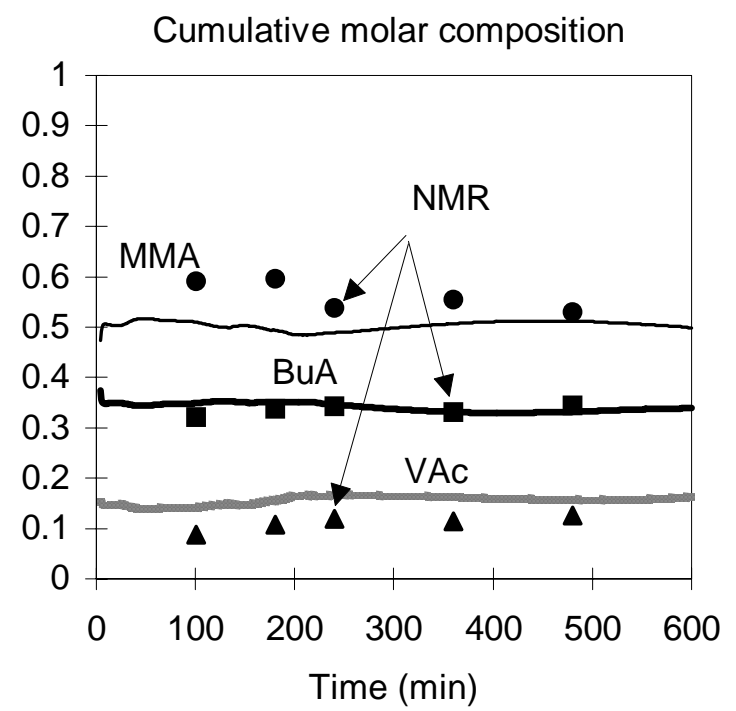

Figure 13: C29. Cumulative molar composition, down. The estimations are represented by the continuous lines and the experimental NMR results are represented by the points.

The composition was controlled simultaneously using $\mathrm{Q}_{1}$ and $\mathrm{Q}_{2}$, the flow rates of MMA and $\mathrm{BuA}$.
The obtained composition is shown in Figure 13. The figure shows the molar fraction of each monomer in the polymer. The estimated values are obtained from the high gain observer. These estimations were validated by off-line NMR. It can be seen also that the cumulative terpolymer composition is sensitive to strong variations in the value of $\mathrm{Q}_{3}$, but is not in good agreement with the experimental NMR measurements. This problem can be solved by reducing the maximum flow rate allowed by the pump controlling $\mathrm{Q}_{3}$. However, this will increase the time required to saturate the polymer particles. Therefore, the choice of the saturation value of $\mathrm{Q}_{3}$ must be a compromise between rapidity of convergence of the controller, and reducing its negative impact on the evolution of the polymer composition.

\section{Conclusion}

In this work we presented several control laws that were successfully applied to homo-, co-, and terpolymerization processes. These control laws allow us to manipulate the concentration of monomer in the polymer particles and to simultaneously maintain the polymer composition at the desired value (in co- and terpolymerization) using calorimetric measurements.

Nonlinear control laws were applied throughout the work. They were easily tuned. The same proportional value was successful for the three types of systems discussed here.

In order to control the process productivity, an improved study about the relation between the concentrations of radicals and monomer is required. This can be done by realizing detailed models or simply by on-line correction of the slope of the reaction rate.

\section{Nomenclature}

\section{Notations}

A surface area between the jacket and the reactor $\left[\mathrm{m}^{2}\right]$

$\mathrm{K}_{\mathrm{pi}}$ reaction rate constant of the active chain $\mathrm{i}$ with monomer i 
$\mathrm{K}_{\mathrm{pij}}$ reaction rate constant between the active chain $\mathrm{i}$ and monomer $\mathrm{j}$

$\mathrm{L}_{\mathrm{f}} \mathrm{h}$ Lie derivative of the scalar field $\mathrm{h}$ with respect to the vector field $\mathrm{f}$

$\left[\mathrm{M}_{\mathrm{i}}^{\mathrm{P}}\right]$ concentration of monomer $\mathrm{i}$ in the polymer particles

$\mathrm{MW}_{\mathrm{i}}$ molecular weight of monomer i

$\overline{\mathrm{n}} \quad$ average number of radicals per particle

$\mathrm{N}_{\mathrm{a}} \quad$ Avogadro's number

$\mathrm{N}_{\mathrm{i}} \quad$ number of moles of free monomer $\mathrm{i}$

$\mathrm{N}_{\mathrm{i}}^{\mathrm{T}}$ total number of moles of monomer $\mathrm{i}$ introduced to the reactor

$\mathrm{N}_{\mathrm{P}}^{\mathrm{T}}$ total number of particles in the reactor

$\mathrm{Q}_{\mathrm{i}} \quad$ molar flow rate of monomer $\mathrm{i}$

$\mathrm{Q}_{\lim }$ maximum heat removed by the jacket [W]

$\mathrm{R}_{\mathrm{pi}} \quad$ rate of reaction of monomer $\mathrm{i}[\mathrm{mol} / \mathrm{s}$ ]

$\mathrm{T}_{\mathrm{j}, \text { min }}$ minimum jacket temperature $\left[{ }^{\circ} \mathrm{C}\right]$

$\mathrm{T}_{\mathrm{R}}$ reactor temperature $\left[{ }^{\circ} \mathrm{C}\right]$

$\mathrm{u}$ input

$\mathrm{U}$ heat transfer coefficient between the jacket and the reactor, $\left[\mathrm{W} / \mathrm{m}^{2} /{ }^{\circ} \mathrm{C}\right]$

$\mathrm{x} \quad$ state variables

$\mathrm{X}$ conversion

y output

$\mathrm{y}^{\mathrm{d}} \quad$ set-point

\section{Greek letters}

$\varepsilon_{\mathrm{i}} \quad$ a function representing the dynamic of $\mathrm{i}$

$\phi_{\mathrm{p}}{ }^{\mathrm{p}}$ volumetric fraction of polymer in the polymer particles

$\kappa_{\mathrm{p}} \quad$ proportional gain of the $\mathrm{P}$ controller

$\mu$ the number of moles of radicals in the polymer particles

$\rho_{\mathrm{i}} \quad$ monomer density $\left(\mathrm{g} / \mathrm{cm}^{3}\right)$

$\rho_{\mathrm{i}, \mathrm{h}} \quad$ homopolymer density $\left(\mathrm{g} / \mathrm{cm}^{3}\right)$

$v \quad$ a linearizing input output transformation

\section{Acronyms}

BuA Butyl acrylate

DSS Dioctyl sulfosuccinate de sodium, (surfactant)

KPS Potassium persulfate, (initiator)

MMA Methyl methacrylate

P proportional controller

SDS Dodecyl sulfate, sodium salt, (surfactant)

STY Styrene

VAc Vinyl acetate

\section{Bibliography}

[1] Gloor, P. E., and R. J. Warner. Developing feed policies to maximize productivity in emulsion polymerization processes. Thermochimica Acta, 289 (1996) 243-265.

[2] Buruaga, I. S., Ph. D. Armitage, J. R. Leiza, J. M. Asua. Nonlinear control for maximum production rate latexes of well-defined polymer composition. Ind. Eng. Chem. Res., 36 (1997) 4243-4254.

[3] Arzamendi, G., and J. Asua. Copolymer composition of emulsion copolymers in reactors with limited capacity for heat removal. Ind. Eng. Chem. Res., 30 (1991) 1342-1350.

[4] Hamielec, A. E., J. F. MacGregor, and A. Penlidis. Multicomponent free-radical polymerization in batch, semi-batch and continuous reactors. Makromol. Chem. Macromol. Symp., 10, 11, (1987) 521-570.

[5] Arzamendi, G. and J. M. Asua. Monomer addition policies for copolymer composition control in semi-continuous emulsion copolymerization. J. Appl. Polym. Sci., 38 (1989) 2019-2036.

[6] Canu, P., S. Canegallo, M. Morbidelli, and G. Storti. Composition control in emulsion copolymerization. I. Optimal monomer feed policies. J. Appl. Polym. Sci. 54 (1994) 18991917.

[7] Lin, C.-C., W.-Y. Chiu. Simulation and optimal design of seeded continuous emulsion polymerization process. J. Appl. Polym. Sci., 27 (1982)1977-1993.

[8] Shork, F. J., and W. H. Ray. The development of the continuous emulsion polymerization of methyl methacrylate. J. Appl. Polym. Sci., 34 (1987) 1259-1276.

[9] Gilmore, C.M., G. W. Poehlein, and J. Schork. Modeling poly(vinyl alcohol)-stabilized vinyl acetate emulsion polymerization. I. Theory. J. Appl. Polym. Sci., 48 (1993) 1449-1460.

[10] Penlidis, A., J. F. MacGregor and A. E. Hamielec. A theoretical and experimental and experimental investigation of the batch emulsion polymerization of vinyl acetate. Polymer Process Engineering, 3, 3 (1985) 185218.

[11] Seminot, D., W. H. Ray. Control of systems described by population balance equations-I. Controllability analysis. Chem. Eng. Sci., 50, 11 (1995a) 1805-1824. 
[12] Seminot, D., W. H. Ray. Control of systems described by population balance equations-II. Emulsion polymerization with constrained control action. Chem. Eng. Sci., 50, 11 (1995b) 1825-1839.

[13] Jang, S. S., P. H.. discontinuous minimum end-time temperature/initiator policies for batch emulsion polymerization of vinyl acetate. Chem. Eng. Sci., 46, 12 (1991) 3153-3163.

[14] Othman N., Santos A. M., Févotte G., McKenna T. F. Monitoring of emulsion polymerisations: A study of reaction kinetics in the presence of secondary nucleation. The Canadian Journal of Chemical Engineening, 80, (2002) 88-104.

[15] Gilbert, R. G.. A mechanistic approach. Colloid Science, R. H. Ottewill, and R. L. Rowell eds (1995).

[16] Gauthier, J.P. and G. Bornard. Observability for any $\mathrm{u}(\mathrm{t})$ of a class of bilinear systems. IEEE Trans Automat Control, 26 (1981) 922-926.

[17] Gauthier, J.P., H. Hammouri and S. Othman. A simple observer for nonlinear systems. Application to bioreactors. IEEE Trans. Automat Control, 37 (1992) 875-880.

[18] Othman, N. PhD Thesis, Université Claude Bernard Lyon-I, July 10, 2000.

[19] Isidori, A.. Nonlinear control systems. An introduction (2nd Edition), Springer-Verlag (1989).

[20] Kravaris C., C.B. Chung. Nonlinear state feedback synthesis by global input/output linearization. AIChE, (1987) 33, 4.

\section{Tables}

Table 1: Homopolymerization recipe for the validation of the estimator of $\mu$.

\begin{tabular}{|l|c|}
\hline \multicolumn{1}{|c|}{$\backslash$ Experiment Component } & $\begin{array}{c}\text { Styrene } \\
\text { Exp. 15 }\end{array}$ \\
\hline Monomer & 600 \\
\hline $\mathrm{H}_{2} \mathrm{O}$ & 2403 \\
\hline Dodecyl sulfate, sodium salt & 4.56 \\
\hline Sodium dioctyl sulfosuccinate & - \\
\hline Potassium persulfat & 4.41 \\
\hline Final solid contents & $20.5 \%$ \\
\hline Final particle size & $107 \mathrm{~nm}$ \\
\hline
\end{tabular}

Table 2: Homopolymerization of polystyrene. Control of $\left[\mathrm{M}_{\mathrm{P}}\right]$.

\begin{tabular}{|l|c|c|}
\hline \multirow{2}{*}{$\begin{array}{c}\text { Experiment } \\
\text { Component }\end{array}$} & \multicolumn{2}{|c|}{ C32 } \\
\cline { 2 - 3 } & $\begin{array}{c}\text { Initial } \\
\text { charge }\end{array}$ & $\begin{array}{c}\text { Preem } \\
\text { ulsion }\end{array}$ \\
\hline Styrene & 104 & 600 \\
\hline $\mathrm{H}_{2} \mathrm{O}$ & 1329 & 300 \\
\hline $\begin{array}{l}\text { Dodecyl sulfate, } \\
\text { sodium salt }\end{array}$ & 3 & - \\
\hline Triton & - & 9.47 \\
\hline Potassium persulfat & 3.03 & - \\
\hline Temperature & \multicolumn{2}{|c|}{$70{ }^{\circ} \mathrm{C}$} \\
\hline Final solid contents & \multicolumn{2}{|c|}{$23 \%$} \\
\hline Final particle size & \multicolumn{2}{|c|}{$88 \mathrm{~nm}$} \\
\hline
\end{tabular}

Table 3: Experiment for the validation of the controller. Copolymerization Recipe.

\begin{tabular}{|c|c|c|c|}
\hline$\backslash$ Run & \multicolumn{3}{|c|}{ C 19 } \\
\hline COMPOSITION & $\mathbf{5 0 - 5 0} \%$ by mol (MMa-BuA) \\
\hline Temperature & \multicolumn{3}{|c|}{$60 \%$} \\
\hline Component $\backslash$ & $\begin{array}{c}\text { Initial } \\
\text { charge }\end{array}$ & Feed 1 (g) & Feed 2 (g) \\
\hline $\mathrm{H}_{2} \mathrm{O}$ & 1500 & 100 & - \\
\hline $\mathrm{Mma}$ & 133 & 354.6 & - \\
\hline BuA & 400 & - & 200 \\
\hline Triton & 7.79 & 8.011 & - \\
\hline DSS & - & 0.636 & - \\
\hline KPS & 3 & - & - \\
\hline Particle size & \multicolumn{3}{|c|}{$398 \mathrm{~nm}$} \\
\hline Solids Contents & \multicolumn{3}{|c}{$40.26 \%$} \\
\hline
\end{tabular}

Table 4: Experiment for the validation of the controller. Terpolymerization Recipe.

\begin{tabular}{|c|c|c|c|}
\hline \multicolumn{1}{|c|}{ Run } & \multicolumn{3}{|c|}{ C 29 } \\
\hline $\mathrm{N}^{\text {SP }}$ & \multicolumn{3}{|c|}{ VAc) } \\
\hline Temperature & $\mathbf{3 0 - 3 5 - 1 5} \%$ by mol (MMa-BuA- \\
\hline Component $\backslash$ & $\begin{array}{c}\text { Initial } \\
\text { charge }\end{array}$ & Feed 1 (g) & Feed 2 (g) \\
\hline $\mathrm{H}_{2} \mathrm{O}$ & 1200 & 400 & - \\
\hline $\mathrm{MMa}$ & 28.6 & 705 & - \\
\hline BuA & 46.1 & 611 & - \\
\hline VAc & 146.2 & - & 300 \\
\hline Triton & 6.63 & 9.43 & - \\
\hline DSS & - & 3.057 & - \\
\hline KPS & 3.0959 & - & - \\
\hline $\begin{array}{c}\text { Final particle } \\
\text { size }\end{array}$ & \multicolumn{3}{|c|}{$320 \mathrm{~nm}$} \\
\hline $\begin{array}{c}\text { Final Solids } \\
\text { Contents }\end{array}$ & \multicolumn{3}{|c}{} \\
\hline
\end{tabular}

